\title{
Developing a generic, individualised adherence programme for chronic medication users
}

\author{
Hanne HERBORG, Lotte S. HAUGBØLLE, Lene SØRENSEN, Charlotte ROSSING, Pernille DAM. \\ Received (first version): 28-Mar-2008 \\ Accepted: $31-J u l-2008$
}

\begin{abstract}
${ }^{*}$
Objective: The scope of this article is to describe the background for and content of an adherence counselling programme with a specific focus on an individualised, multi-dimensional adherence model for patients with a potential adherence problem (a so-called 'individualised systems model'). Methods: An intervention programme based on WHO's systems model for adherence was developed for implementation in primary health care and tested in a development project in Danish pharmacies in 2004-2005 in three pharmacies and 4 GP practices by 27 patients. Data were collected from the participants by registration forms, questionnaires, and focus groups. Since the programme was to support patients in the selfmanagement process regarding choice and implementation of medication treatment, various strategies were used and different theoretical assumptions and choices made prior to setting up the study. These strategies include distinguishing between different types of non-adherence, a model for stages of change, self-efficacy, narratives, motivating interviewing strategies and coaching techniques. These strategic and theoretical choices are described in the article.

Results: The strategies and theoretical reflections formed the platform for the creation of a counselling programme, which was tested in two forms, a basic and an extended version - provided by either a pharmaconomist or a pharmacist. The result section also describes a toolbox of instruments to enable pharmacy staff and GPs to tailor a counselling programme for patients individually called 'Safe and effective use of medicines'. Besides, the results include a description of how the WHO-model is transformed into an individualised counselling model.
\end{abstract}

Keywords: Patient Compliance. Counseling. Self Efficacy. Denmark.

\footnotetext{
*Hanne HERBORG. MSc (pharm). Director of R\&D, Pharmakon. Hillerød, (Denmark).

Lotte S. HAUGBØLLE. PhD (pharm). Associate Professor, Copenhagen University. Copenhagen (Denmark). Lene SØRENSEN. PhD (pharm). Consultant R\&D; Pharmakon. Hillerød, (Denmark). Charlotte ROSSING. PhD (pharm). Section Manager, Pharmakon. Hillerød, (Denmark). Pernille DAM. MSc (public health science). Consultant R\&D, Pharmakon. Hillerød, (Denmark).
}

\author{
DESARROLLO DE UN PROGRAMA DE \\ ADHERENCIA GENÉRICO E \\ INDIVIDUALIZADO PARA USUARIOS DE \\ MEDICACIÓN CRÓNICA
}

\section{RESUMEN}

Objetivo: El ámbito de este artículo es describir los antecedentes y el contenido de un programa de consejo en adherencia específicamente enfocado a un modelo multidimensional individualizado de adherencias para pacientes con un posible problema de adherencia (conocido como "modelo de sistemas individualizado').

Métodos: Se desarrolló un programa de intervención basado en el modelo de sistemas de la OMS para adherencia y se probó en un proyecto danés desarrollado en 2004-2005 en 3 farmacias y 4 consultas de médicos generales con 27 pacientes. Se recogieron los datos de los participantes en formularios, cuestionarios y grupos focales. Como el programa era para apoyar a los pacientes en el proceso de auto-gestión en cuanto a la selección, e implantación del tratamiento medicamentoso, se usaron varias estrategias y se hicieron a priori varias asunciones teóricas y elecciones para arrancar el estudio. Estas estrategias incluyeron diferenciar los distintos tipos de no-adherencia, un modelo de estados de cambio, auto-eficacia, narrativas, estrategias de entrevistas motivadoras, y técnicas de entrenamiento. Estas estrategias y elecciones teóricas se describen en el artículo. Resultados: Las estrategias y reflexiones teóricas crearon la plataforma para la creación de un programa de consejo, que se probó de dos formas, una versión básica y una extensa - proporcionado bien por un farmacoeconomista o un farmacéutico. La sección de resultados también describe un conjunto de instrumentos para capacitar al personal de la farmacia y a los médicos a dirigir un programa de consejo para pacientes denominado 'Uso efectivo y seguro de medicamentos'. Además, los resultados incluyen una descripción de cómo se transformó el modelo de OMS en un modelo de consejo individualizado.

Palabras clave: Cumplimiento del paciente. Consejo. Auto-eficacia. Dinamarca.

\section{INTRODUCTION}

Poor adherence to the treatment of chronic diseases is a worldwide problem of significant 
magnitude, about $50 \%$ on average in developed countries and even higher in developing countries. ${ }^{1}$ The consequences of poor adherence to long-term therapies are poor health outcomes and increased health care costs, among other things.

Adherence is defined as '.. the extent to which a person's behaviour - taking medication, following a diet and/or lifestyle changes, corresponds with agreed recommendations from a health care practitioner'. ${ }^{1-3}$ Adherence, thus, requires the patient's agreement to the recommendation. Since 1997, where the concept was launched for the first time in the UK, 'concordance' has been used to describe this process of shared decision making concerning medicine use. ${ }^{4}$ Adherence and concordance need to go hand in hand. We use the term adherence throughout the article, also when comparing our results to the results of other studies in which only the term compliance has been used.

With the model shown in Figure 1, WHO argues for a systems approach to studying adherence, an approach made up of the interplay between the following five dimensions: patient-related factors; social/economic factors; therapy-related factors; condition-related factors and health-system related factors. ${ }^{1}$ Therefore, a suitable programme and model for identifying and solving non-adherence needs should take its starting point in these dimensions.

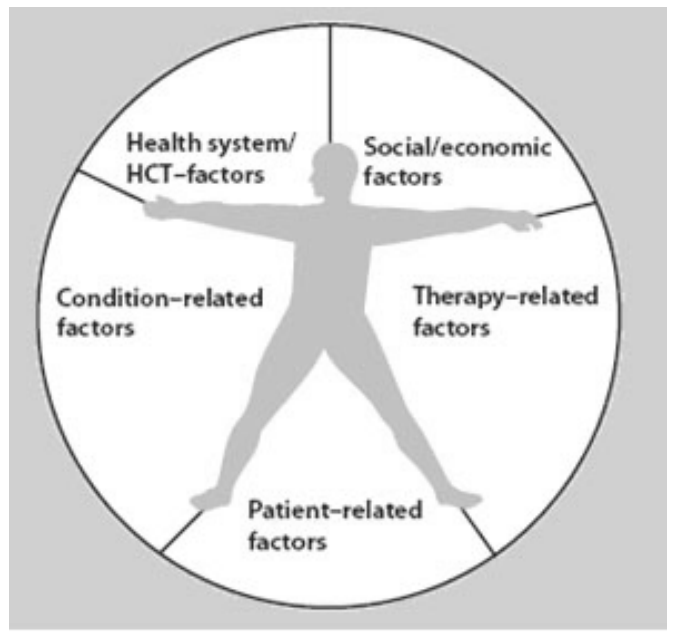

Figure 1. The five dimensions of adherence as suggested by the World Health Organisation

According to $\mathrm{WHO}^{1}$, non-adherence should not be viewed as an isolated, single-factor problem, but rather as a multi-dimensional problem not determined exclusively by patient factors, as is seen most often in adherence research. WHO's systems model (Figure 1) aims to analyse and provide explanations for non-adherence on a societal and health policy level in a broader sense. To our knowledge, however, to date international literature does not describe how the model can be and has been operationalised on the individual patient level. On the basis of the achievements described below, we have reason to believe that patients can achieve competence and motivation that improves selfmanagement and adherence through a counselling programme rooted in primary health care with the pharmacy as a coordinating point of care. The programme identifies potential non-adherence, analyses the character of the problems identified, including drug-related problems, explores patient resources and provides concordance-based followup sessions and individually based interventions.

Using a systems approach to study the processes of medication on the individual patient level is a well-known phenomenon in the pharmacy research area. In recent years, a system-oriented approach as suggested by WHO has been operationalised and used on the individual patient level in several pharmaceutical care projects aiming to prevent and solve drug-related problems and consequently avoid drug-related morbidity and mortality ${ }^{5}$ and likewise a systems approach is used in the patient safety and medication error literature.

Studies have shown how community pharmacies, in close collaboration with GPs, play an important role in improving adherence, through detecting quality problems in the drug use process and through supporting patients' self-management with relevant, individually tailored solutions. ${ }^{6-11}$

An intervention programme was developed for implementation in primary health care and tested in a development project in Danish pharmacies in 2004-2005. Overall, the development project aimed at developing and validating a pharmacy-based primary care programme with the objective of ensuring safe and effective medicine use among users of hypertensive medicines.

The scope of this article is to describe the strategic and theoretical background for and content of an adherence counselling programme with a specific focus on an individualised, multi-dimensional adherence model for patients with a potential adherence problem, exemplified by a concrete case illustrating the use of the model.

\section{METHODS}

\section{Design}

The development project was set up as a formative evaluation, the main purpose of which is learning from and optimising an intervention.

From December 2004 through May 2005, three pharmacies implemented, tested and validated the programme in cooperation with $4 \mathrm{GP}$ practices. Twenty-seven patients with potential for nonadherence were included in the study. Of this number, 23 users of anti-hypertension medication followed the entire programme (44\% female, $56 \%$ male). Mean age was 59.2 years (range: 44 to 74 years).

Patient inclusion took place in the pharmacy and was based on suspected patient non-adherence detected by a so-called Quick Screening Instrument (QSI). QSI is a short questionnaire on the patient's adherence behaviour, developed on the basis of validated instruments from other adherence projects described in the literature and from medication information about the patient. Originally, GPs were to include patients in the project, but they had 
difficulty identifying a sufficient number of patients within the allotted time frame, so the inclusion strategy was changed to make pharmacies responsible for the inclusion of patients. Antihypertensive patients were chosen because despite the risk of cardio-vascular diseases and other illnesses associated with hypertension, a high prevalence of non-adherence to antihypertensive medication has been reported in the literature (between 30-70\%). ${ }^{1,12}$

\section{Strategic and theoretical choices}

Recent larger reviews show that interventions to improve adherence need to draw on a long list of technical, behavioural, cognitive and emotional tools, often in combination, and always dependent on the character of the specific problem(s) experienced by the patient. ${ }^{13-18}$ The process of the intervention in the development study was summarised in the following short formula: "Find the patient, get the story, check for errors, find the resources together with the patient, share goals, agree on plan, get it done and follow up".

\section{Pharmaceutical care and patient safety}

A special priority was to create a counselling programme based on a pharmaceutical care platform $^{19}$ combined with a strong focus on the patient resources that enable the individual patient to improve his/her adherence. The programme was thus intended to support patients in the selfmanagement process regarding choice and implementation of medication treatment, but it also used a check for drug related problems to avoid working for adherence with inappropriate drug therapies. To reach this goal, various strategies were used and different theoretical assumptions and choices were made prior to creating the programme. These strategies include the use of narratives, coaching techniques and motivating interviewing strategies (including stages of change and self-efficacy as key concepts) and distinguishing between different types of non- adherence. The strategic and theoretical choices are described below.

\section{Narratives}

Patient narratives about medication use were used as a kick-off for the intervention, and several interviewing and counselling techniques were used to collect them - pharmacists used coaching in the extended version of the programme and pharmacoeconomists used motivating interview strategies in the basic version of the programme. Many fields use narrative storytelling, which has been gaining influence in the health care area in recent years. ${ }^{20-22}$ The theory of narration is based on the assumption that everyone - including patients - has a story to tell. People organise their world in stories that then form the basis of their actions. By letting patients tell their story, health care practitioners can use coaching to help identify key issues and facilitate a process in which the patient creates a more suitable version of the story and discovers resources and solutions.

\section{Coaching}

The pharmacists in the programme used coaching techniques throughout the intervention. In brief, coaching is a narrative and systemic tradition in which professionals ask linear, circular, reflective and strategic questions that facilitate realisation in the client (in this case patients). ${ }^{23}$ Patients choose from among the solutions they have come up with during the coaching session, which they feel themselves capable of implementing in daily life. In the end, the counsellor and the patient can hopefully agree on a plan to solve the problem. Thus, the coaching process is ultimately a means of creating a concordant process and partnership between the patient and the pharmacist.

Table 1 shows the different types and formulation of questions used when coaching patients in the programme.

\begin{tabular}{|l|ll|}
\hline \multicolumn{3}{|l|}{ Table 1: Coaching questions (types and formulation) } \\
\hline Type of coaching question & \multicolumn{2}{c|}{ How the question was formulated } \\
\hline Reactions from others & $*$ & If your doctor were here now, what would he think about your BP and your treatment? \\
& $*$ & Would he be satisfied? \\
& $*$ & What would he think should be done? \\
& $*$ & If we asked your family/network, what would they say? \\
& $*$ & Are they worried about your blood pressure? \\
& $*$ & Do they have wishes or suggestions that you often hear? \\
\hline Weighing pros and cons & $*$ & What do the 'errors' you make today benefit you? \\
& $*$ & On a scale from 0-10, how do you rate the importance of bringing down your BP? \\
\hline In the best of all worlds... & $*$ & What will the drug treatment of your BP be like (In 5 years? In 6 months?) \\
& $*$ & What would be the most important change needed to make things go that well? \\
& $*$ & What would be the smallest change needed to make things move forward? \\
\hline Noticing success & $*$ & Who would notice if you were taking a drug therapy that you were happy about? How? \\
& $*$ & What would they see you doing? \\
\hline Seeing possible goals & $*$ & Based on our talk, what would you suggest we do to get the best possible outcome? \\
\hline Assessing options & What would happen if... \\
& $*$ & we had your doctor change your medicine? \\
& $*$ & we sent you an SMS every day? \\
& $*$ & you had your medicine dispensed in a dose administration aid? \\
& $*$ & I gave you more information about your illness and your medicine? \\
& $*$ & you came here to the pharmacy to have your BP measured? \\
\hline
\end{tabular}




\section{Motivating interview strategies}

Since patient self-efficacy and outcome expectations determine patient actions, motivating interview strategies ${ }^{24}$ are especially useful techniques for approaching people who are nonadherent. Motivation dialogue is based on the premise that patients are basically responsible for their own health, and thus also in charge of changing inappropriate behaviour. In other words, this type of counselling fully accepts and acknowledges patient autonomy, as does the theory of concordance. However, patients need to be given enough information to be able to make an informed decision, and it is the health care professional who offers the patient an informed position. Therefore, the health care professional must use the patient's perspective as a very important starting point for actions that the patient considers realistically doable.

\section{Stages of change}

One main model that has been used extensively with regard to changing health behaviour is the Stages of Change Model, also called the Transtheoretical Model of Change (TTM). ${ }^{25}$ The TTM has proven useful for describing change in behaviour in a wide range of areas such as alcohol and substance abuse, anxiety and panic disorders, eating disorders, HIV/AIDS prevention, mammography screening and smoking cessation. ${ }^{25}$ The model has not been used widely to examine the medication use process, however. Thus, Ficke and Farris $^{26}$ identified only 11 articles dealing with the model and drug use, none of which involved intervention studies to improve adherence based on the model. The model explains the process in any behavioural change, based the six following phases: pre-contemplation, contemplation, preparation, action, maintenance and relapse. ${ }^{25}$ Precontemplation is the period in which an individual is not thinking about changing behaviour. Contemplation is the period of time an individual is seriously thinking about changing behaviour within a given period of time such as six months, for example. In the preparation phase, one seriously considers changing behaviour in the next month or so. Action is the time from inception to six months during which a person takes action to change behaviour. Maintenance is defined as the period of time six months after an action is started and until the problem is solved. ${ }^{27}$

The model presumes that individuals are located at different motivational stages throughout a behavioural change circle. These different motivations are to be taken into account when providing information to, counselling and/or coaching patients with the aim of helping them progress through the motivational stages.

\section{Self-efficacy}

In dialogue with people who are non-adherent it is crucial to identify potential self-efficacy problems. Perceived self-efficacy refers to beliefs in one's abilities to organise and execute the courses of action required to manage prospective situations. ${ }^{28}$
Our self-efficacy heavily influences how we feel, think and act, and is therefore a crucial factor in any self-management approach. If people feel that they are in control of a situation, that they can actually solve a problem by their actions (showing a high degree of self-efficacy), they are more willing to change and feel more committed to adherence. A high degree of self-efficacy leads to more appropriate self-management, and has been shown to be a strong predictor for adherence as well as for a positive treatment result. ${ }^{1,29,30}$ For this purpose, the programme has a number of tools to support information giving and patient education.

\section{Types of non-adherence}

Distinguishing between different types of nonadherence as a basis for developing the counselling programme is a relatively new view of nonadherence, one supported by $\mathrm{WHO}^{1}$ : Nonadherence is seen as a systems problem, not as just a simple 'error' in a patient needing more knowledge to change behaviour. In the drug-related problem identification phase and counselling phase of the project, a distinction is made between intentional and un-intentional non-adherence. ${ }^{41}$ It is crucial for health care professionals to distinguish between the different types of non-adherence in order to help patients find proper solutions for their specific type of problem.

The compliance process as such can be roughly divided into the following three phases: Acceptance, implementation and persistence. ${ }^{32}$ Identifying which phase the patient is in may determine what solutions to problems the health care practitioner can help the patient recognise. Research has shown that increased adherence is related to patient acceptance and strong involvement regarding treatment and communication between patient and health care provider. ${ }^{43,34}$ With intentional non-adherence, the patient has made a deliberate choice to not follow the otherwise agreed recommendations on medicine use, whereas the patient practising un-intentional non-adherence either forgets and/or is not paying attention. Typically, intentionally non-adherent patients ${ }^{31}$ have made their decisions based on several subjective feelings and experiences (such as misunderstandings, negative feelings, lack of support, lack of confidence in the health care system and personnel, lack of confidence in medications, low self-esteem, bad experiences). With non-intentional non-adherence, forgetfulness is often the problem and the patient may only need help for the execution of the treatment. Hence packaging and reminder technologies may be helpful. Thus, very different approaches are needed to improve adherence depending on the patient's type of non-adherence.

\section{RESULTS}

The two versions of the counselling programme

Table 2 represents a toolbox of instruments to enable pharmacy staff and GPs to tailor a counselling programme for patients individually. 
Table 2: Toolbox with instruments for counselling

Evaluating medicines and drug-related problems:

- QSI (compliance status, problems with blood pressure control, general satisfaction with treatment)

- Pharmaceutical care technology:

- $\quad$ Check for interactions, dose regimens and adverse reactions

- $\quad$ Check the personal electronic medication profile

Counselling and coaching of the patient:

- Interview guide:

- Motivation interview technique using key words: stages of change, concordance, self-efficacy

- Coaching

Patient education and information:

- Written, video and internet-based information sources

- Internet site for patients

Reminder technologies:

- Dose dispensing aids

- SMS reminders, telephone reminders

- MEMS and feedback

- Blood pressure measurements

- Patient diaries (paper/internet)

Communication tools:

- GP communication regarding prescription evaluation

- Health promotion services: Referral of lifestyle-related problems, e.g. smoking, overweight and lack of exercise.

\begin{tabular}{|c|c|c|}
\hline & Basic version & Extended version \\
\hline Provided by & Pharmacoeconomists & Pharmacists \\
\hline \multirow[t]{2}{*}{ Estimated time } & $\begin{array}{l}\text { About } 80 \text { minutes in total, distributed over at least } \\
\text { four meetings }\end{array}$ & $\begin{array}{l}\text { About four hours in total, distributed over at } \\
\text { least four meetings }\end{array}$ \\
\hline & \multicolumn{2}{|c|}{ Process } \\
\hline Medicine use check & $\begin{array}{l}\text { Identify potential non-adherence using the Quick } \\
\text { Screening Instrument } \\
\text { Check personal electronic medication record for } \\
\text { adherence problems } \\
\text { Check personal medication record for medication- } \\
\text { related issues }\end{array}$ & $\begin{array}{l}\text { Identify potential non-adherence using the } \\
\text { Quick Screening Instrument } \\
\text { Check personal electronic medication record for } \\
\text { adherence problems } \\
\text { Medication review (therapeutic and economic } \\
\text { issues) }\end{array}$ \\
\hline $\begin{array}{l}\text { Blood pressure } \\
\text { measurement }\end{array}$ & Using a manual & Using a manual \\
\hline Interview & Short basic interview & Comprehensive interview \\
\hline Knowledge & $\begin{array}{l}\text { Provide information } \\
\text { Pamphlets }\end{array}$ & $\begin{array}{l}\text { Patient education in areas dealing with } \\
\text { increased blood pressure, medication, self- } \\
\text { management } \\
\text { Provide information } \\
\text { Pamphlets }\end{array}$ \\
\hline Motivation & $\begin{array}{l}\text { Dialogue based on "the motivating dialogue" } \\
\text { Joint agreements }\end{array}$ & $\begin{array}{l}\text { Dialogue based on "the motivating dialogue" as } \\
\text { well as on coaching techniques } \\
\text { Joint agreements }\end{array}$ \\
\hline Habits & $\begin{array}{l}\text { Support to remember medication intake: } \\
\text { * Dose dispensing systems. } \\
\text { * Medication event monitoring systems } \\
\text { (MEMS) and feedback } \\
\text { * Blood pressure measurements at home } \\
\text { * Individually-based memo techniques } \\
\text { * Paper- or net-based diaries containing own } \\
\text { data } \\
\text { * SMS service or e-mail service }\end{array}$ & $\begin{array}{l}\text { Support to remember medication intake: } \\
\text { * Dose dispensing systems. } \\
\text { * Medication event monitoring systems } \\
\text { (MEMS) and feedback } \\
\text { * Blood pressure measurements at home } \\
\text { * Individually-based memo techniques } \\
\text { * Paper- or net-based diaries containing } \\
\text { own data } \\
\text { * SMS service or e-mail service }\end{array}$ \\
\hline & & $\begin{array}{l}\text { Referral to other services, e.g. smoking } \\
\text { cessation }\end{array}$ \\
\hline Contact with GP & $\begin{array}{l}\text { Feedback to GP regarding dialogue and referral } \\
\text { of patient if deemed necessary }\end{array}$ & $\begin{array}{l}\text { Feedback to GP regarding dialogue and referral } \\
\text { of patient if deemed necessary }\end{array}$ \\
\hline
\end{tabular}


The strategies and theoretical reflections described above formed the platform for the creation of a counselling programme. The programme was then tested in two forms; a basic and an extended version, in the interests of cost-effectiveness (see Table 3). Patients were assigned to either the basic or the extended version of the programme. Obviously, if the basic, focused programme provided by pharmaconomists in this project was cost-effective, there would be no reason to offer the more extended, coaching and medication review based programme provided by pharmacists.

The content of the counselling programme emerged as a result of an evaluation of the development project in which the following data collection instruments were used: questionnaire assessing patient medication use and adherence (QSI); data from personal electronic patient records; intervention registration schemes; satisfaction questionnaires (for patients, GPs and pharmacy staff); chat-rooms; log-books and focus group dialogue between researchers and project participants. $^{35}$

As might be seen from Table 3, the basic and extended versions of the programme share many similarities. The extended version, though, is much more comprehensive and detailed than the basic version and, thus, more time-consuming for health care professionals and patients alike. It namely covers all the aspects of the basic version plus some additions, such as the option of using coaching techniques as a tool for problem solving and a thorough medication review (including economic and therapeutic elements).

During the first dialogue between patient and pharmacy staff, primary foci were collecting patient data and measuring blood pressure levels. The pharmacies would have access to the QSI- data and with the patient's consent, to the personal medication profile of each patient. This initial screening was supplemented by an interview, its length and content dependent on whether the patient had been allocated to the basic or the extended programme. During the next contact between patient and pharmacy staff, an assessment was made of adherence and the effect of the adherence support provided. In some cases assessment included a dialogue with the patient's GP. In all encounters with patients, strong emphasis was put on hearing the patient's version of the story: how does the patient feel about his/her blood pressure, medical treatment, illness history, etc. However, equal emphasis was given to the drug expert perspective.

\section{Transforming the WHO systems model into a generic, individualised adherence model/programme}

The model developed and used as a template for the entire programme was called the 'individualised systems model' (Figure 2). It emerged from the transformation of the WHO model into an individualised counselling model.

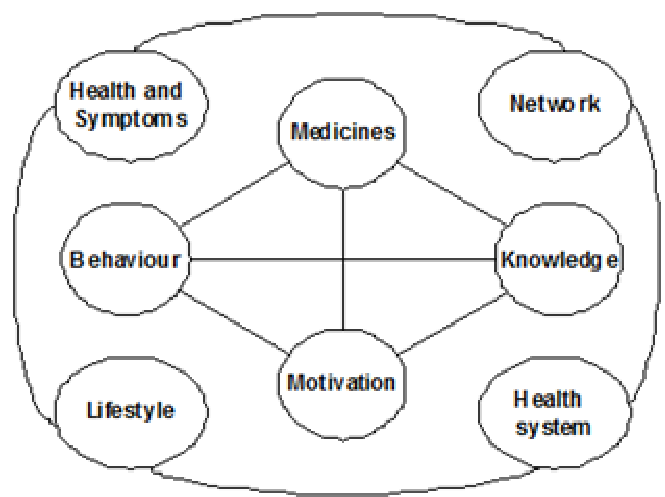

Figure 2: The individualised systems model

The systems model supports lateral thinking in the search for causes and resources for problem solving, and functions as a key tool in the programme.

There is an overweight of patient-related factors in the individualised systems model shown in Figure 2 because the model is used to counsel individual patients.

The 'inner circle' in the model in Figure 2 is the first focus of pharmacy staff in their search for causes and resources, when dealing with a potentially nonadherent patient.

Figure 3 illustrates possible solutions to issues raised from the inner circle. Finding possible solutions is handled in collaboration with the patient. The systems model is thus not a theoretical model, but a tool for practical patient counselling. Although the problems experienced by the patient might be many and complex, solution(s) to the problems are to be simple and straightforward as possible, in order to promote successful implementation.

That said, however, particularly when providing the extended version of the counselling programme, pharmacy staff often found a need to include questions and problem-solving tools related to the outer circle (issues related to lifestyle, health systems, family involvement, collegue involvement, referral to other health care professionals, coaching on transitions e.g. from home to hospital use of medication profile,network, etc.), especially when searching for resources.

\section{An example of the systems model used in practice}

To illustrate how the individualised systems model was used to identify the most appropriate solutions, we will now describe a case from the development project. Case 'Jane' was offered the extended version of the programme.

Jane is woman in her $60 \mathrm{~s}$, housewife, formerly a health worker. She is referred by the GP for her poor blood pressure control and suspected nonadherence. She uses thiazides and beta-blockers. Jane seems motivated, knows the importance of taking her medication and considers herself adherent, but forgets to take her medications 
unintentionally when her daily routines are interrupted. Jane knows the importance of being adherent from her previous job as a health worker. However, pharmacy staff identifies potential 'holes' in her personal electronic medication profile for her hypertension medicines, indicating under-use. It appeared that Jane normally took her medicines as planned, but '... of course slips and lapses happen when you are busy and your attention is elsewhere', Jane explains. Jane thought these few lapses could not really make a difference, but she knows that her
GP thought her blood pressure was too high, which she found somewhat worrying. The pharmacist then had a long talk with Jane about how she could avoid forgetting to take her medicines when she was busy. On normal days the blue container by the coffee machine did the job.... 'I chose the ugly blue colour on purpose - so I would notice and remember to take my medicine'. Only Jane often missed doses when she was not at home, taking care of her grandchildren once or twice a week, for example.

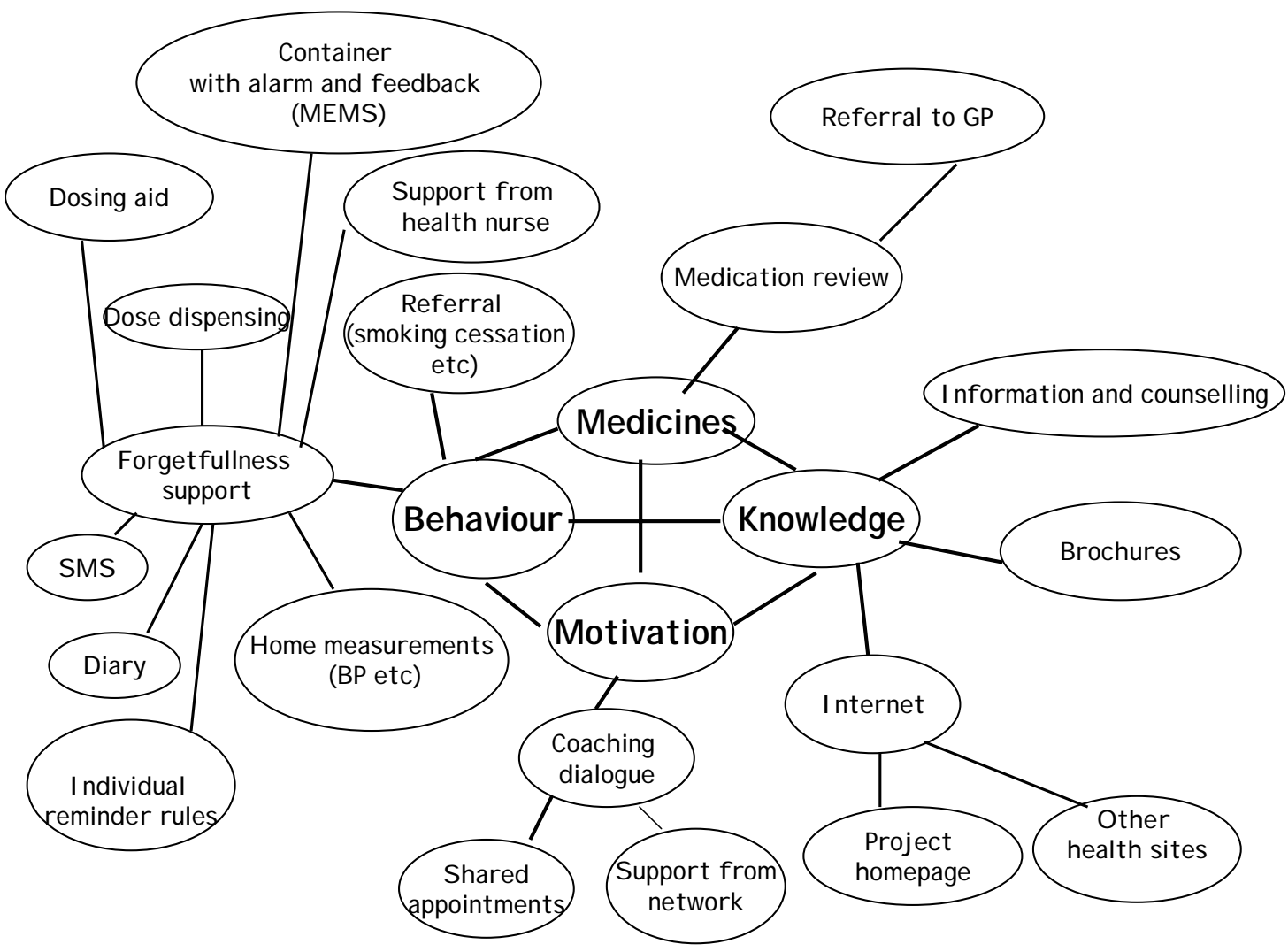

Figure 3: Mind-map of solutions offered by the programme, related to inner circle issues

Jane is not interested in all the 'fancy' technologies the pharmacist suggests from the list of reminder tools. She likes homemade systems and decides to put 'ugly blue' reminders by her toothbrush and in her car to have two extra chances to remember her medicine.

\section{Interpretation of Jane's case}

Jane had no motivational problems or lack of knowledge about medicines, but she did have a knowledge problem: a misunderstanding of the impact of missed doses now and again. Once Jane understood the importance of not missing doses, she faced a behavioural problem, namely the need for stronger reminder solutions in specific situations.

The coaching approach was useful with Jane, especially in the phase where resources and solutions were being sought. Jane was asked coaching questions that picked up on her own version of the story, as well as questions that made her step into the role of 'significant others' (see Table 1). Other types of coaching questions were based on motivational interviewing, of which some aimed at finding out how Jane would be motivated to change and finding the best options for making the change (see Table 1).

As can be seen from the above case description, it is important not to return to simplistic models, but to have a professional routine to find the right tools for the individual patient. This case clearly shows how much individually based 'tailoring' is needed to find the best solutions for each patient individually.

\section{DISCUSSION}

A review of 33 selected randomised controlled trials of interventions to assist patients with adherence to prescribed medications has stated that almost all the interventions effective for long-term care were complex, including combinations of more 
convenient care, information, counselling, reminders, self-monitoring, reinforcement, family therapy, and other forms of additional supervision or attention. ${ }^{13}$ Nonetheless, even the most effective interventions had modest effects. This review is supported by results from a recent Cochrane review $^{36}$, which included 57 un-confounded randomised trials reporting on adherence and treatment outcomes with a follow-up period of at least six months. First, less than half $(45 \%)$ of the interventions described in the review resulted in improved adherence, and only 33\% in better treatment outcomes. ${ }^{36}$ Second, those interventions effective for long-term care were exceedingly complex and labour-intensive, and, third, even the most effective interventions did not lead to major improvements in adherence and treatment outcomes. These reviews give us reason to believe that the adherence problem-solving phase does not necessarily need to be complex and multifaceted in character. However, the adherence problem and patient resource identification phase need to stand on a rather complex platform in order for health care personnel to understand each patient's perspective, and in order to enable the patient to open up for and use his/her own resources to address the adherence issue. This assumption is also supported by a review of 49 randomised trials on cardiac care, which found that enhancing self-efficacy, skills training and self-monitoring is a successful strategy for increasing medication adherence. ${ }^{37}$

The individualised systems model described in this article is one model for approaching the identification phase of the adherence problem in a complex yet individualised way. A recent metareview of 38 systematic reviews of the effectiveness of adherence interventions stated that the most effective adherence interventions are simplifying dosage and packaging and establishing reminders. ${ }^{38}$ Developing simple interventions was also given first priority by a recent International Expert Forum on Patient Adherence ${ }^{39}$, whose members were asked to comment on the main findings in the meta-review by van Dulmen et al. ${ }^{38}$ In addition, the expert forum supported future theory development in the adherence field, especially the creation of conjoint knowledge of medical, pharmaceutical, social and technological sciences, just as the expert panel also supported the exploration of increased patient participation in the development of (new) interventions. ${ }^{38}$

Recently, the so-called Phamionic Knowledge Centre has accumulated electronically compiled drug dosing histories of more than 16000 patients in 10 major fields of pharmacotherapy. MEMS $\AA$ were used to compile the drug dosing histories during the course of 90 drug studies performed between 1990 and 2005, with study durations ranging from 30 to 1400 days. The current data set results in more than 3.5 million days of compiled dosing histories. ${ }^{40}$ According to Vrijens and Urquhart ${ }^{41}$ the three phases of ambulatory pharmacotherapy consist of adherence, acceptance and execution. 'Adherence' is a blanket term covering any type of error; 'Acceptance' initiates the process; 'execution' characterizes the process; 'discontinuation' terminates the process. The length of time from beginning to ending of 'execution' is termed 'persistence'. The compiling of the huge amount of data show a $10-15 \%$ lack of adherence due to errors in the execution. Burnier et al. ${ }^{42}$ have also shown that half of the failures with hypertensive treatments are due to poor execution of the regimen. We agree with Vrijens and Goethebeur ${ }^{43}$ that poor execution has the unique feature of creating a series of natural experiments in dose ranging, revealed and made amendable to analysis when dosing histories are electronically compiled, thus turning a source of noise and confusion into a unique, potentially major source of learning.

\section{Transferability of the model}

Both the basic and the extended versions of the counselling programme are potentially useful in a broader primary care setting and with most chronic patients (chronic care model). Developing a concordance partnership between GPs, pharmacy staff and potentially non-adherent hypertensive patients was actually another of the development project goals. One initial challenge was the GP's inconsistency in referring potentially non-adherent patients to the programme. Nonetheless, the programme contributed to some useful clarification of the extent and level of contact between GPs and the pharmacy in connection with pharmacy staff interventions for potentially non-adherent patients. The research literature indicates that collaborative care is an effective adherence intervention in primary care. For instance, a review of 19 randomised trials in the area of anti-depressants stated that in 9 out of 13 primary care studies, a significant difference was seen between intervention and usual care groups with an increased adherence of approximately $25 \%$ for the intervention group and with the intervention group being subject to collaborative care. ${ }^{44}$

The tools developed in the project have recently been tested in 12 Danish pharmacies in two randomised controlled research programmes for 240 users of anti-hypertensive medicines and 80 type 2 diabetics. The results (including outcomes results) from these two research programmes will be presented in the near future. The preliminary results from the two research programmes give us strong reason to believe that the programme 'Safe and effective use of medicines' has potential as a generic, individualised adherence programme for different types of chronic medication users.

\section{CONCLUSIONS}

The article describes the content and the strategic and theoretical background of a pharmacy based adherence-counselling programme with specific focus on the creation of an individualised, multidimensional adherence model (called 'Safe and effective use of medicines') for patients with a potential adherence problem. Both a basic and an extended version of the counselling programme were implemented in a Danish primary care setting and were successful in developing a concordance 
partnership between patents, GPs, and pharmacy staff.

\section{CONFLICT OF INTEREST}

There are no conflicts of interest. Financial support was granted by The Association of Danish Pharmacists, Hørslevfonden and Pharmadanmark.

\section{References}

1. WHO. Adherence to long-term therapies - evidence for action. Noncommunicable diseases and mental health adherence to long term therapies project. Report. Geneva: World Health Organisation; 2003.

2. Haynes RB. Determinants of compliance: The disease and the mechanics of treatment. Baltimor (MD): Johns Hopkins University Press; 1979.

3. Rand CS. Measuring adherence with therapy for chronic diseases: implications for the treatment of hetrozygous familial hypercholesterolemia. Am J Cardiol 1993; 72:68D-74D.

4. Marinker M, Blekinsopp A, Bond C, Britten N, Feely M, George C. From compliance to concordance: achieving shared goals in medicines taking. London: Royal Society of Great Britain; 1997.

5. Hepler CD, Grainger-Rousseau TJ. Pharmaceutical care versus traditional drug treatment. Is there a difference? Drugs 1995;49(1):1-10.

6. Carter BL, Barnette DJ, Chrischilles E, Mazotti GJ, Asali ZJ. Evaluation of hypertensive patients after care provided by community pharmacists in a rural setting. Pharmacotherapy 1997;17:1274-1285.

7. Park JJ, Kelly P, Carter BL, Burgess PP. Comprehensive pharmaceutical care in a chain setting. J Am Pharm Assoc. 1996;NS36:443-451.

8. Ringer J, Keys P, Wagenknacht LD, Miller DE, Slaughter RL.The Michigan Pharmacists' Association Patient Persistency Project. J Managed Care Pharm. 2001;7(1):50-55.

9. Munroe WP, Kunz K, Dalmady-Israel C, Potter L, Schonfeld WH. Economic evaluation of pharmacist involvement in disease management in community pharmacy setting. Clin Ther. 1997;19:113-123.

10. Søndergaard B, Thorleifsson S, Herborg H, Frøkjær B, Hepler CD, Ersbøll BK. Kvalitetssikring af astmapatienters lægemiddelbehandling. Sundhedsøkonomisk analyse. Ugeskr Læger. 2000;162:480-486.

11. Herborg H, Soendergaard B, Groekjaer B, Fonnesbaek L, Jorgensen T, Hepler CD, Grainger-Rousseau TJ, Ersboell BK. Improving drug therapy for patients with asthma - Part I: Patient outcomes. J Am Pharm Assoc. 2001;41:539-550.

12. Stason WB. Compliance, quality of life and cost effectiveness. Curr Hypertens Rep. 1999;1:471-474.

13. McDonald HP, Garg AX, Haynes RB. Interventions to enhance patient adherence to medication prescriptions. JAMA. 2002;288:2868-2879.

14. Haynes RB, McKibbon KA, Kanani R. Systematic review of randomised trials of interventions to assist patients to follow prescriptions for medication. Lancet. 1996;348(10):383-386.

15. Schroeder K, Fahey T, Ebrahim S. How can we improve adherence to blood pressure-lowering medication in ambulatory care? Systematic review of randomized controlled trials. Arch Intern Med. 2004;164:722-732.

16. Pampallona S, Bollini P, Tibaldi G, Kupelnick B, Munizza C. Patient adherence in the treatment of depression. Br J Psychiatry 2002;180:104-109.

17. DiMatteo MR. Variations in patients' adherence to medical recommendations - a quantitative review of 50 years of research. Med Care 2004 Mar;42(3):200-209.

18. Weingarten SR, Henning JM, Badamgarav E, Knught K, Hasselblad V, Gano Jr A, Ofman JJ. Interventions used in disease management programmes for patients with chronic illness - which ones work? Meta-analysis of published reports. Br Med J 2002 Oct;325:925.

19. Hepler CD, Segal R. Preventing medication errors and improving drug therapy outcomes: a managemetn systems approach. Boca Raton, 2003.

20. Charon R. Narrative medicine - a model for empaty, reflection, profession and trust. JAMA 2001;286(15):1897-1902.

21. Greenhalgh T, Hurwitz B, editors. Narrative based medicine: dialogue and discourse in clinical practice. London: BMJ Books; 1998.

22. Kleinman A. The illness narratives: suffering, healing and the human conditions. New York (NY): Basic Books; 1988.

23. Tomm K. Interviewet som intervention - er hensigten at stille lineære, cirkulære, strategiske eller refleksive spørgsmål? Forum 1992;4: 3-13.

24. Miller WG, Rollnick S. Motivational interviewing preparing people to change addictive behaviour. New York: Guilford; 1991.

25. Prochaska JO, DiClimente CC, Norcross JC. In search of how people change. Am Psychol 1992;47:1102-1104.

26. Ficke DL, Farris KB. Use of the transtheoretical model in the medication use process. Ann Pharmacother. 2005;39:1325-1330.

27. Prochaska JO, Redding CA, Evers KE. The transtheoretical model and stages of change. In: Glanz K, Rimer BK, Lewis, editors. Health behavior and health education: theory, research, and practice, 3rd ed. San Fransisco: Jossey Bass; 2002. p. 99-116.

28. Bandura A. Self-efficacy: towards a unifying theory of behavioral change. Psychol Rev. 1977;84:191-215.

29. Barlow JH, Cullen LA, Rowe IF. Educational preferences, psychological well-being and sef-efficary among people with reumatoid arthritis. Patient Educ Couns. 2002;46:11-19.

30. Vermeien E, Hearnshaw H, Van Royen P, Denekens J. Patient adherence to treatment: three decades of research. A comprehensive review. J Clin Pharm Ther. 2001; 26:331-342. 
31. Barber N. Should we consider non-compliance a medical error? Qual Saf Health Care. 2002;11:81-84.

32. Waeber B, Brunner HR, Métry JM. Compliance with antihypertensive treatment: implications for practice. Blood Press. 1997;6:326-331.

33. Marinker M, Shaw J. Not to be taken as directed. Putting concordance for taking medicines into practice. BMJ. 2003;326:348-349.

34. Benson J, Britten N. Patients' decisions about whether or not to take antihypertensive drugs: a qualitative study. BMJ. 2002;325:873-878.

35. Pharmakon. Udviklingsrapport "Sikker og effektiv medicinbrug" for brugere af blodtryksmedicin - version 1.1; 2007.

36. Haynes R, Yao X, Degani A, Kripalani S, Garg A, McDonald H. Interventions to enhance medication adherence. Cochrane Database Syst Rev. 2005. 2005:1-96.

37. Burke LE, Dunbar-Jacob-JM, Hill MN. Compliance with cardiovascular disease prevention strategies: a review of the research. Ann Behav Med. 1997;19:239-263.

38. van Dulmen S, Sluijs E, van Dijk L, de Ridder D, Heerdink R, Bensing J. Patient adherence to medical treatment: a review of reviews. BMC Health Serv Res. 2007;7:1-13.

39. Sluijs E, van Dulmen S, van Dijk L, de Ridder D, Heerdink R, Bensing J. Patient adherence to medical treatment: a meta review. 2006. Report by NIVEL. Available from: http://www.nivel.nl/

40. Vrijens B, Tousset E, Gaillard P-A, Métry J-M, Urquhart J. Major Features of Dose Omissions in 87 Ambulatory Drug Trials. Clinl Pharmacol Ther. 2005;77(2): P99, abstract LB.6.

41. Vrijens B, Urquhart J. Impact of diverse temporal patterns of dosing on drug actions. Leiden/Amsterdam Center for Drug Research, Vrije Universiteit Amsterdam. Homepage available from http://www.lacdr.nl/index.php3?c=92 (Viewed on March 14, 2008).

42. Burnier M, Schneider MP, Chiolero A, Stubi CL and Brunner HR. Electronic compliance monitoring in resistant hypertension: the basis for rational therapeutic decisions. J Hypertens. 2001; 19: 335-341.

43. Vrijens B and Goetghebeur E (2004) Electronic monitoring of variation in drug intakes can reduce bias and improve precision in pharmacokinetic/pharmacodynamic population studies. Stat Med. 23:531-544.

44. Vergouwen AC, Bakker A, Katon WJ, Verhaij TJ, Koerselman F. Improving adherence to antidepressants: a systematic review of interventions. J Clin Psychiatry. 2003;64:1415-1420. 